Published in final edited form as:

Mov Disord. 2005 September ; 20(9): 1161-1169.

\title{
Antidepressant Studies in Parkinson's Disease:
}

\author{
A Review and Meta-Analysis
}

Daniel Weintraub, MD $1,4,{ }^{*}$, Knashawn H. Morales, $\mathrm{ScD}^{5}$, Paul J. Moberg, PhD ${ }^{1,3}$, Warren B. Bilker, $\mathrm{PhD}^{5}$, Catherine Balderston, $\mathbf{M S}^{1}$, John E. Duda, MD ${ }^{2,3}$, Ira R. Katz, MD, $\mathrm{PhD}^{1,4}$, and Matthew B. Stern, MD2,3

1Department of Psychiatry, University of Pennsylvania, Philadelphia, Pennsylvania, USA

2Department of Neurology, University of Pennsylvania, Philadelphia, Pennsylvania, USA

3Parkinson's Disease Research, Education and Clinical Center (PADRECC), Philadelphia Veterans Affairs Medical Center, Philadelphia, Pennsylvania, USA

4Mental Illness Research, Education and Clinical Center (MIRECC), Philadelphia Veterans Affairs Medical Center, Philadelphia, Pennsylvania, USA

5Department of Biostatistics and Epidemiology, University of Pennsylvania, Philadelphia, Pennsylvania, USA

\section{Abstract}

The objective of this study was to determine effect sizes for both antidepressant treatment and placebo for depression in Parkinson's disease (PD), and to compare the findings with those reported in elderly depressed patients without PD. Recent reviews have concluded that there is little empiric evidence to support the use of antidepressants in PD; however, available data has not been analyzed to determine the effect size for antidepressant treatment in PD depression. A literature review identified antidepressant studies in PD. Suitable studies were analyzed using meta-analytic techniques, and effect sizes were compared with those from antidepressant studies in elderly patients without PD. Large effect sizes were found for both active treatment and placebo in PD, but there was no difference between the two groups. In contrast, active treatment was superior to placebo in depressed elderly patients without PD. In PD, increasing age and a diagnosis of major depression were associated with better treatment response. Results also suggest that newer antidepressants are well tolerated in PD. Despite the high prevalence of depression and antidepressant use in PD, controlled treatment research has been almost non-existent. Meta-analysis results suggest a large but nonspecific effect for depression treatment in PD. In addition, PD patients may benefit less from antidepressant treatment, particularly selective serotonin reuptake inhibitors, than do elderly patients without PD.

\section{Keywords}

Parkinson's disease; depression; antidepressive agent; treatment; effect size; meta-analysis

It is estimated that 30 to $40 \%$ of patients with Parkinson's disease (PD) suffer from some form of depression 1,2 and 20 to $25 \%$ of patients receiving specialty care are taking an antidepressant. 3,4 Despite the high prevalence of depression and antidepressant use in PD, many questions remain concerning the diagnosis and treatment of depression in this population. For instance, accurately diagnosing depression in PD can be difficult, as there is symptom overlap between core PD and depression symptoms (e.g., psychomotor changes, fatigue, insomnia, and apathy).

\footnotetext{
*Correspondence to: Dr. Daniel Weintraub, 3535 Market St., Room 3003, Philadelphia, PA 19104. E-mail: weintrau@mail.med.upenn.edu
} 
In addition, recent research suggests that most cases of depression in PD may represent episodes of minor or recurrent brief depression ${ }^{1,5}$ calling into question the usefulness of antidepressant treatment for many PD patients with depression.

Although there is an extensive literature on the epidemiology and phenomenology of depression in PD, ${ }^{6-12}$ there have been relatively few treatment studies. In the psychosocial realm, a small pilot study suggested that cognitive psychotherapy might be helpful for depression in $\mathrm{PD},{ }^{13}$ but there have been no controlled studies of psychosocial treatments.

Concerning antidepressant treatment in PD, almost all existing studies have been either uncontrolled (i.e., open-label) or underpowered placebo-controlled studies. 5,14 The use of open-label studies is particularly problematic in PD, as a high placebo response rate has been reported in this population. ${ }^{15}$ In addition, a key outcome measure is the impact of antidepressant treatment on parkinsonism, which is best assessed in a blinded, placebocontrolled trial.

A 1995 review (covering 1966 to June 1993) of published studies identified only 12 depression treatment studies in PD, 4 of which were thought to have adequate methodology. ${ }^{16}$ The authors concluded, "The main conclusion to be drawn from this review is that presently there is no empirical evidence on which to base a treatment plan for depression in patients with Parkinson's disease." A 2002 review (years covered in review not specified) of depression treatment in PD identified 19 antidepressant studies, only 5 of which were thought suitable for inclusion in the review. ${ }^{17}$ Regarding newer antidepressants, the authors stated, "There is insufficient evidence available to conclude on the efficacy of SSRIs as a class for treatment of depression in patients with Parkinson's disease." Finally, a 2003 Cochrane Database review (covering 1800s to February 23, 2001) of antidepressant therapies for depression in PD identified three randomized controlled trials of oral antidepressant medications and concluded, "Insufficient data on the effectiveness and safety on any antidepressants therapies in Parkinson's disease are available on which to make recommendations for their use." 18

The aforementioned reviews used different criteria to rate the quality of individual studies and did not attempt to analyze statistically the available data to determine the effect of antidepressant treatment. To assess the impact of antidepressant treatment in PD, we reviewed the English language literature on depression in PD and employed meta-analytic procedures, incorporating the effect size of each study as the unit of analysis to examine the influences of pharmacologic treatment on depression in PD. Effect size is defined as the magnitude of the mean difference between pre- and post-assessment measures, expressed in standard deviation units. ${ }^{19}$ In the current meta-analysis, the primary effect size examined was the difference between pre- and posttreatment scores on depression rating scales in depressed PD patients.

The aims of this meta-analysis were to examine the difference between active and placebo treatment on depression in PD, to compare these findings to treatment studies involving elderly depressed patients without $\mathrm{PD}$, and to probe for moderators of antidepressant treatment response in PD.

\section{MATERIALS AND METHODS}

\section{Literature Search}

A literature review (1 January 1965 to 31 December 2003) of English-language studies concerning the treatment of depression and the use of antidepressants in PD was conducted on July 1, 2003 and January 1, 2004 using online databases (Medline, PubMed, and PsycINFO) and reference lists from reviewed articles. Primary search terms were Parkinson's disease, depression, antidepressive agents, and therapy. 
To be included in the general review, a study had to enroll subjects with parkinsonism, use a medication with reported antidepressant effects, and report the outcome of antidepressant treatment. Levodopa (L-dopa) and dopamine agonists were not included due to their confounding impact on motor function and the lack of consensus over antidepressant effects.

To be included in the meta-analysis, a study had to include patients with idiopathic PD only, be a depression treatment study and enroll subjects diagnosed with depression, use a medication approved as an antidepressant in the United States or Europe, and report the change over the course of treatment based on a standardized rating scale of depression severity. Although more restrictive criteria were considered, using them would have eliminated almost all studies from inclusion, and the authors decided that less restrictive criteria would have would have made the sample too heterogeneous in terms of neurological diagnosis, medication utilized for the treatment of depression, and the measurement of treatment outcome.

There were two reviewers for the articles (D.W. and P.J.M.). The reviewers met monthly during the literature review, statistical analysis, and article preparation, and there was agreement between the reviewers on the findings of the reviewed articles.

\section{Statistical Analysis}

Analyses were conducted according to procedures suggested by Rosenthal ${ }^{20}$ and Hedges and Olkin. ${ }^{21}$ Comprehensive Meta-Analysis v. 1.10 software (Biostat, Englewood, NJ) was used to calculate effect sizes and to carry out subsequent homogeneity and moderator variable analysis. The dependent measure was effect size for baseline and posttreatment ratings of depression expressed in Cohen's $d .{ }^{22,23}$ Traditionally, Cohen's $d$ index is the difference between patient and control group means, within each study or comparison, expressed in standard deviation units. Here, $d$ is expressed as the change from baseline for each study. If the means and standard deviations were not reported, approximate $P$ values were converted to $d$ using formulas provided by Glass. ${ }^{22}$ By expressing effect size in standard deviation units, we were able to make a direct comparison of outcomes across studies. The analysis proceeded in two steps. First, Cohen's $d$ was derived for each study by subtracting the mean baseline depression score $\left(m_{b}\right)$ from the mean follow-up depression score $\left(m_{p}\right)$, and dividing it by the pooled standard deviation $(s)$ using the formula of Rosnow and Rosenthal 24 :

$$
d=\frac{m_{b}-m_{p}}{s \sqrt{\frac{d f}{N}}}
$$

where $s=\left[\left(n_{b}-1\right) s_{b}^{2}+\left(n_{p}-1\right) s_{p}^{2}\right] /\left(n_{b}+n_{p}-2\right) d f=$ degrees of freedom and $N=$ the total number of observations. An effect size $\geq 0.80$ was considered large, as described by Cohen's metric. $^{25}$

Individual values of $d$ were hereafter combined across studies and weighted according to their variance estimate $(v)$ using the formulas:

$$
d_{s}=\frac{\sum w_{i} d_{i}}{\sum w_{i}}
$$

where $w_{i}=\frac{1}{v_{i}}$ represents the individual weight for a given study and vi is the variance of $d_{i}$. 21

Potential differences in effect size between treatment and placebo administration were analyzed using the method of Hedges and Olkin. ${ }^{21}$ This procedure computes mean weighted effect sizes and $95 \%$ confidence intervals (CI) for each level of a variable (i.e., treatment condition), and 
allows for the testing of the influence of each individual factor on the overall results. The $95 \%$ $\mathrm{CI}$ is calculated as

$$
d_{S} \pm 1.96 \sqrt{v_{S^{\prime}}}
$$

where $v_{s}=\frac{1}{\sum w_{i}}$

\section{Moderator Variable Analysis}

Age, gender, and severity of PD (i.e., Hoehn and Yahr stage) have been cited as possible contributors or moderator variables in the expression of depression in PD. These variables, plus sample composition (major depression only vs. mixed depression) and duration of trial, were therefore examined as potential moderators of the obtained effect sizes. Continuous data (i.e., mean age of sample, percentage of sample that was male, mean Hoehn and Yahr stage, and mean duration of clinical trial) were analyzed with a meta-regression model, which is equivalent to a weighted least-squares regression model with weights equal to $w_{i}$. ${ }^{26}$ For each continuous moderator variable of interest, the following model was estimated:

$$
\theta_{i}=\beta_{0}+\beta_{1} x_{i}
$$

where $\theta_{i}$ represents the effect size estimate for each study and xi is the moderator variable of interest. A nonsignificant test of $H_{0}: \beta_{1}=0$ suggests there is insufficient evidence of a relationship between the predictor variable and effect size. Meta-regression models were fit in SPLUS v6 (Insightful Corp., Seattle, WA).

Group comparisons were made for categorical moderator variables (e.g., sample composition). In these comparisons, an analysis of variance (ANOVA)-type summary is estimated for the group effect. 27

Significance tests for these analyses were two-tailed. Given the small number of study groups in the meta-analysis that were administered placebo, only the active treatment groups were subjected to moderator variable analysis. $P$ values $\leq 0.05$ were considered significant.

To gauge the relative magnitude of the observed treatment effects for depression in patients with PD, effect sizes were also calculated for the two largest placebo-controlled antidepressant studies in elderly outpatients with major depression but without PD. ${ }^{28,29}$

\section{RESULTS}

\section{Review of Studies}

Publication Date-Between 1 January 1965 and 31 December 2003, a total of 27 studies were identified $5,14,30-54$ that met inclusion criteria. Although the examined timeframe was 37 years, half $(14 / 27,51.9 \%)$ of the studies had been published in the past seven years. 5,14 , $32,34,36-38,41,47,48,50-52,54$

Study Design-Approximately half $(16 / 27,59.3 \%)$ of the studies were designed as antidepressant studies; the rest were designed primarily to measure the change in PD symptoms and did not specifically include patients with a depression diagnosis, although they did include change in depression as a secondary outcome measure. $30,33,34,39,40,42,43,45,46,49,53$

Eleven of the studies were double-blind placebo-controlled, $5,14,30,31,35,42,43,45,46,49,53$ one combined subjects from a double-blind placebo-controlled and an open-label study, 40 one was a double-blind comparison study, 39 two were single-blind placebo-controlled, 33,34 and twelve were open-label studies. ${ }^{32,36-38,41,44,47,48,50-52,54}$ 
Twenty-four of the studies specified trial duration, and their mean (range) duration was 12.6 (range, 1-65) weeks. Another study treated patients for between 2 and 5 months, ${ }^{34}$ and one other did not provide any information about duration of treatment. ${ }^{46}$

Sample Size-In total, 772 subjects enrolled in the studies, and there were 668 completers (overall completion rate $=86.5 \%$ ). Mean study sample size was 28.6 (range, 8-93).

Inclusion Criteria-Thirteen (48.1\%) of the studies used formal diagnostic criteria to define depression (12 Diagnostic and Statistical Manual for Mental Disorders [DSM-IV or DSMIIIR] criteria $5,14,35-38,41,47,50-52,54$ and 1 Feighner's criteria ${ }^{44,55}$ ). For the studies using DSM criteria, six included patients with major depression only, $5,14,38,47,51,52$ four enrolled patients with major depression or dysthymia, $36,37,41,50$ and two included patients with a depression diagnosis but did not specify further. ${ }^{35,54}$ Three studies using formal diagnostic criteria also used a minimum score on a depression rating scale as an additional inclusion criterion. $44,47,54$ Three other studies used only a minimum score on a depression rating scale as an inclusion criteria and did not formally diagnose depression. ${ }^{31,32,48}$ The other 11 studies were not designed as depression studies and either did not attempt to diagnose depression at baseline or did not specify such attempts. $30,33,34,39,40,42,43,45,46,49,53$

For the six studies that required a minimum score on a scale of depression severity as an inclusion criterion, three required a minimum score on the Hamilton Depression Rating Scale $^{56}$ (two >16, one >17), 44,47,54 one a Montgomery Asberg Depression Rating Scale 57 score $>7,32$ one a Geriatric Depression Scale-Short Form ${ }^{58}$ score $>4,48$ and one an Andersen Depression Scale ${ }^{59}$ score $>12.31$

Study Medication-Approximately half (15/27, 55.6\%) of the studies used FDA-approved medications for the treatment of major depression. Ten studies utilized selective serotonin reuptake inhibitors (SSRIs); four used citalopram, $5,32,50,51$ three sertraline, ${ }^{14,41,48}$ two paroxetine, ${ }^{36,54}$ and one used four different SSRIs. ${ }^{37}$ Four studies used tricyclic antidepressants (one each imipramine, ${ }^{53}$ desipramine, ${ }^{45}$ amitriptyline, ${ }^{43}$ and nortriptyline ${ }^{31}$ ), and bupropion was utilized in one study. 40

Examining dosages for the antidepressants most commonly used in these studies (i.e., SSRIs), all studies included dosages within the therapeutic range for geriatric depression as recommended by experts but only one ${ }^{32}$ included a dosage within the highest recommended range. 60

Examining non-FDA-approved medications, three studies used antidepressants prescribed outside of the United States (one each moclobemide, ${ }^{52}$ reboxetine, ${ }^{47}$ and nomifensine ${ }^{34}$ ). PD medications were assessed for antidepressant effects in seven studies (six used selegiline ${ }^{30}$, $33,39,42,46,49$ and one, bromocriptine ${ }^{44}$ ). Finally, $S$-adenosyl-ı-methionine (SAMe), an amino-acid derivative that has been studied for its antidepressant effects, was used in two studies. 35,38

Outcome Measures-Most studies (22/27, 81.5\%) used a depression severity rating scale as the primary outcome measure. Thirteen studies used the Hamilton Depression Rating Scale, 5,30,35-38,42,44,47,50-52,54 four the Zung Scale, ${ }^{39,43,46,49}$ two the Montgomery Asberg Rating Scale, ${ }^{14,32}$ and one each the Anderson Scale, ${ }^{31}$ the Beck Depression Inventory, ${ }^{41}$, 62 and the Profile of Mood States. 33,63 The other five studies did not use a formal outcome measure. $34,40,45,48,53$

Only 2 of 22 studies using a depression severity rating scale defined response a priori either as a minimum percentage of improvement in the scale or a study completion scale score below 
a specified number. ${ }^{14,51}$ The 5 studies that did not use a formal outcome measure defined response as being "improved,"40,45,48 "cured," 34 or as the "degree of relief." 53

Statistical Analysis-Statistical tests used were Mann-Whitney $U$ or Wilcoxon signed-rank tests, $5,31,32,38,41,43,47,49$ analysis of variance for repeated measures, $30,33,35-37,39,50 t$ test, ${ }^{42,44,52}$ and $\chi^{2}$ test. ${ }^{14}$

Six studies reported "percentage improved," $34,40,45,48,51,53$ and two others did not specify the statistical technique used. ${ }^{46,54}$ Only two of these studies were designed as antidepressant studies 48,51 and only one reported a $P$ value for depression outcome. ${ }^{54}$

Results-Fourteen $(14 / 20,70.0 \%)$ of the studies using statistical tests reported $P<0.05$ in favor of treatment, $30,33,35-37,41,50$ including seven with $P<0.01 .31,32,38,44,47,52,54$ The other six studies reported nonsignificant $P$ values. $5,14,39,42,43,49$ For the six studies reporting "percentage improvement," four studies reported that a total of 59.0\% (36/61) of subjects improved with treatment, $, 40,48,51,53$ one reported "no improvement" with treatment, ${ }^{34}$ and the other reported the percentage improvement only for a subset of the sample. ${ }^{45}$

Examining double-blind, placebo-controlled studies $(\mathrm{n}=11)$, six reported no statistically significant difference between active and placebo treatment, $5,14,42,43,46,49$ three reported $P<0.05,30,31,35$ one stated that $60.0 \%$ (12/20) of subjects "improved" on active treatment but did not specify improvement on placebo, ${ }^{53}$ and one study did not report results. ${ }^{45}$

\section{Meta-Analysis}

Of 27 antidepressant studies originally identified, $11^{5,14,32,36,37,41,47,50-52,54}$ met criteria for inclusion in the meta-analysis. Two 5,14 of the studies included in the meta-analysis were placebo-controlled, and the active and placebo treatment arms for these studies were analyzed separately. Altogether, 309 subjects were enrolled, 260 in open-label and 49 in placebocontrolled studies. The characteristics and effect sizes for each of the 13 study treatment groups (11 active treatment and 2 placebo) are presented in Table 1.

Excluded studies were those that utilized as antidepressants medications that are prescribed primarily to treat the motor symptoms of $\operatorname{PD}(n=730,33,39,42,44,46,49)$ or are not approved for the use of depression in the United States or Europe $\left(n=2^{35,38}\right)$, presented incomplete or unusable data $\left(\mathrm{n}=6^{31,34,40,45,48,53}\right)$ or used grossly inadequate antidepressant dosages (n $=1^{43}$ ).

\section{Group Treatment Effects}

Analysis of both active treatment and placebo condition revealed a very large composite effect size $\left(d_{+}=+0.95 ; 95 \% \mathrm{CI}=+0.76<\delta<+1.14\right)$, reflecting significant reductions in depression ratings after both antidepressant treatment and placebo administration. Between-treatment analysis, however, indicated that the effect size for active treatment was not significantly different from that for placebo $\left(Q_{B}=0.59, P=0.44\right.$; Table 2$)$.

Homogeneity analysis, testing the equality of effect sizes across studies, revealed significant heterogeneity of effect sizes in the active treatment studies $(Q[10]=29.80, P<0.001)$. The hypothesis of homogeneity was rejected at the $5 \%$ level, indicating differences between the study effect sizes. Removal of three outliers $36,37,41$ yielded a more homogeneous sample $(Q$ $[7]=10.2, P=0.18)$ with the mean effect size for active treatment studies increasing by $44 \%$ with removal of these outliers $\left(d_{+}=+1.34,95 \% \mathrm{CI}=+1.07<\delta<+1.61\right)$.

The composite effect size for the placebo treatment groups was homogeneous $(Q[1]=0.47$, $P=0.49)$. Repeat contrasts between active treatment and placebo groups for the homogeneous 
solutions remained not significant $\left(Q_{B}=0.43, P=0.51\right)$, indicating that both conditions produced very large, but similar, reductions in depression severity.

\section{Moderator Variable Analysis}

Age-The mean age across studies ( $\mathrm{N}=11$ studies) was 66.1 years. The impact of age on the obtained effect sizes for active treatment was significant $(t=1.92, P=0.05)$, with older age being associated with a larger effect size.

Gender-The composition of samples with regard to men and women was assessed by calculating the percentage of men in each sample and relating this to effect size. The percentage of men in the studies ( $\mathrm{N}=9$ studies) combined was $54 \%$, suggesting an equitable balance between men and women in the studies analyzed. Examination of gender effects on treatment response did not reveal any significant impact of this factor on effect size $(Z=1.16, P=0.25)$.

Severity of PD-The average Hoehn and Yahr score was 2.3. Severity of PD did not have a significant impact on the obtained effect sizes $(\mathrm{N}=8$ studies; $t=1.62, P=0.11)$.

Diagnostic Composition of Sample-To examine the possible impact of diagnostic composition of the samples ( $\mathrm{N}=11$ studies) on effect size, each study sample was classified as consisting of patients with: (1) major depression only, or (2) mixed depression (any combination of major depression, minor depression, dysthymia, and no criteria specified). Five studies were comprised of patients with major depression only, and six had a mixed depression sample. Analysis of effect size by diagnostic composition revealed significant differences between major depression and mixed depression $\left(Q_{B}=12.2, P<0.001\right)$, with the studies comprised of a mixed depression sample having much smaller effect sizes $\left(d_{+}=+0.84,95 \%\right.$ $\mathrm{CI}=+0.63<\delta<+1.06)$ than did those consisting of patients with major depression only $\left(d_{+}\right.$ $=+1.49,95 \% \mathrm{CI}=+1.19<\delta<+1.79)$.

Duration of Trial-The mean trial duration across studies $(\mathrm{N}=11$ studies $)$ was 11.9 weeks. The impact of duration on the obtained effect sizes for active treatment was significant $(t=$ $-3.81, P<0.001$ ), with longer studies associated with a smaller effect size.

\section{Comparison with Treatment Effects in Non-PD Geriatric Depression Studies}

The effect sizes for both active treatment $\left(d_{+}=+1.42,95 \% \mathrm{CI}=+1.31<\delta<+1.53\right)$ and placebo $\left(d_{+}=+1.24,95 \% \mathrm{CI}=+1.13<\delta<+1.34\right)$ conditions in non-PD elderly patients with major depression were larger than were those found in PD. In addition, active treatment was significantly superior to placebo condition in the non-PD population $\left(Q_{B}=5.73, P=0.02\right)$.

\section{DISCUSSION}

Our literature review identified fewer than 30 studies over the past 40 years involving use of a medication with reported antidepressant effects for the treatment of depression in PD. Most published studies were conducted in the past decade, which coincided with the introduction of SSRIs and other newer antidepressants.

Concerning study design, only one-half were designed as antidepressant studies, and one-third used a medication not approved for the treatment of depression in the United States or Europe. Fewer than half the studies were placebo-controlled, and the average sample size was less than 30 subjects. Less than half the studies used formal diagnostic criteria to diagnose depression, and less than one-fifth used a depression rating scale to set a minimum depression severity for study inclusion. Although most studies used a rating scale of depression severity to assess outcome, almost none defined a priori what constituted response to treatment. 
Of 27 studies originally identified, only 11 were determined to be suitable for inclusion in the meta-analysis. The most common reasons for excluding studies were study designs testing the impact of an antidepressant on parkinsonism instead of depression, the use of PD or unapproved medications as antidepressants, and inadequate or insufficient data to compute a treatmenteffect size.

The results of the meta-analysis results suggest a very large effect for both active treatment and placebo in PD depression, but no difference between the two. Creating homogenous samples by removing the three outlying studies from the active treatment analysis increased the effect size for active treatment substantially, but there still was no difference between the two conditions. Nonspecific treatment elements, not medication effect, thus may be the reason for the positive response reported in PD antidepressant studies. The number of placebocontrolled studies, however, was very small.

In contrast, the largest placebo-controlled antidepressant studies in elderly patients without PD found active treatment to be superior to placebo. As both PD and non-PD depressed patients showed a similar robust response to placebo condition, the difference seemed to be that PD patients did not respond as well to active treatment as did non-PD patients. This was despite the fact that the overwhelming majority of PD patients included in the meta-analysis who were treated with an antidepressant were in open-label studies, whereas the non-PD patients taking an antidepressant were enrolled in placebo-controlled studies, which typically report lower response rates. Removal of the three outlying studies did make the effect sizes for active treatment comparable in the two groups, suggesting that variability in study design (e.g., use of mixed depression samples) may help explain the lower response rates to active treatment in PD.

Examining moderators of treatment response, age and diagnostic composition were two of the variables associated with treatment response. Specifically, increasing age was associated with a better response to treatment, showing that old age should not be considered a barrier to treatment for depression in PD.

Studies that enrolled patients with a variety of depression diagnoses (i.e., mixed depression samples) showed less treatment effect than did those that restricted enrollment to patients with major depression. This is not surprising, as it is thought that patients with minor depression or dysthymia are less likely to respond to antidepressant treatment than are patients with more severe depression. ${ }^{64,65}$ All three outlier studies had mixed depression samples, suggesting that part of the failure to demonstrate a difference between active treatment and placebo conditions in PD was due to the inclusion of patients with less severe forms of depression in some studies.

Concerns linger about the ability of PD patients to tolerate newer antidepressants, particularly in terms of worsening parkinsonism. ${ }^{66}$ Although the data on tolerability did not lend itself to statistical analysis, it is important to note that for the studies included in the meta-analysis, $87.3 \%$ (227/260) of subjects completed open-label trials, including 86.3\% (202/234) of those taking an SSRI. In addition, 79.2\% (19/24) of subjects in placebo-controlled trials completed active treatment. These findings suggest that PD patients in general are able to tolerate SSRI treatment.

The meta-analysis was limited by the overall lack of consistency in following guidelines for the statistical reporting of clinical trials, ${ }^{67}$ particularly for older studies. Second, the analysis used effect size formulas for independent samples, but the effect size estimates were based on change in depression score from baseline, which are not independent measures. Third, pooling the estimates of the variances from the two time points yields an overestimate of the true variance of the difference. Fourth, there were two studies with sample sizes less than 10; 
however, there was very little difference in the effect size estimate for the active treatment after removing the small studies $\left(d_{+}=+0.89,95 \% \mathrm{CI}=+0.69<\delta<+1.10\right)$. Fifth, a limitation of all meta-analyses is that only published studies are included, so the possibility of publication bias suggests that active treatment effect sizes may actually be less than reported here. Finally, almost all studies included in the meta-analysis used SSRIs, limiting the conclusions that can be drawn about antidepressant treatment in general.

In conclusion, although depression and antidepressant use is common in PD, there have been surprisingly few antidepressant studies and almost no controlled research in this population. Meta-analysis results suggest that antidepressant treatment has a very large but nonspecific positive effect on depression in PD. In addition, PD patients may benefit less from antidepressant treatment than elderly depressed patients without PD do, although this may be due partly to diagnostic heterogeneity in study populations.

The paucity of existing data highlights the need to conduct large-scale, placebo-controlled antidepressant studies in PD, to compare multiple classes of medications due to the unique pathophysiological changes in this disease, and to establish moderators and mediators of treatment response. To accomplish the latter, studies should include subjects with a wide range of ages, cognitive abilities, depression severity, and PD clinical characteristics.

\section{Acknowledgments}

This work was supported in part by the National Institute of Mental Health (MH067894) and the Mental Illness Research, Education, and Clinical Center (MIRECC) at the Philadelphia VAMC.

\section{REFERENCES}

1. Tandberg E, Larsen JP, Aarsland D, Cummings JL. The occurrence of depression in Parkinson's disease. a community-based study. Arch Neurol 1996;53:175-179. [PubMed: 8639068]

2. Slaughter JR, Slaughter KA, Nichols D, et al. Prevalence, clinical manifestations, etiology, and treatment of depression in Parkinson's disease. J Neuropsychiatry Clin Neurosci 2001;13:187-196. [PubMed: 11449025]

3. Richard IH, Kurlan R, Parkinson Study Group. A survey of antidepressant use in Parkinson's disease. Neurology 1997;49:1168-1170. [PubMed: 9339713]

4. Weintraub D, Moberg PJ, Duda JE, et al. Recognition and treatment of depression in Parkinson's disease. J Geriatr Psychiatry Neurol 2003;16:178-183. [PubMed: 12967062]

5. Wermuth L, Sørensen PS, Timm S, et al. Depression in idiopathic Parkinson's disease treated with citalopram: a placebo-controlled trial. Nord J Psychiatry 1998;52:163-169.

6. Cummings JL, Masterman DL. Depression in patients with Parkinson's disease. Int J Geriatr Psychiatry 1999;14:711-718. [PubMed: 10479741]

7. Starkstein SE, Preziosi TJ, Bolduc PL, et al. Depression in Parkinson's disease. J Nerv Ment Dis 1990;178:27-31. [PubMed: 2295885]

8. Poewe W, Luginger E. Depression in Parkinson's disease. Neurology 1999;52(Suppl):2-6.

9. Tandberg E, Larsen JP, Aarsland D, et al. Risk factors for depression in Parkinson disease. Arch Neurol 1997;54:625-630. [PubMed: 9152120]

10. Mayeux R, Stern Y, Williams JBW, et al. Clinical and biochemical features of depression in Parkinson's disease. Am J Psychiatry 1986;143:756-759. [PubMed: 2424323]

11. Hoogendijk WJ, Sommer IEC, Tissingh G, et al. Depression in Parkinson's disease: the impact of symptom overlap on prevalence. Psychosomatics 1998;39:416-421. [PubMed: 9775698]

12. Leentjens AF, Marinus J, Van Hilten JJ, et al. The contribution of somatic symptoms to the diagnosis of depression in Parkinson's disease: a discriminant analytic approach. J Neuropsychiatry Clin Neurosci 2003;15:74-77. [PubMed: 12556575]

13. Dreisig H, Beckmann J, Wermuth L, et al. Psychologic effects of structured cognitive psychotherapy in young patients with Parkinson's disease. Nord J Psychiatry 1999;53:217-221. 
14. Leentjens AF, Vreeling FW, Luijckx GJ, et al. SSRIs in the treatment of depression in Parkinson's disease. Int J Geriatr Psychiatry 2003;18:552-554. [PubMed: 12789682]

15. de la Fuente-Fernández R, Stoessl AJ. The placebo effect in Parkinson's disease. Trends Neurosci 2002;25:302-306. [PubMed: 12086748]

16. Klaassen T, Verhey FR, Sneijders GH, et al. Treatment of depression in Parkinson's disease: a metaanalysis. J Neuropsychiatry Clin Neurosci 1995;7:281-286. [PubMed: 7580184]

17. Treatment of depression in idiopathic Parkinson's disease. Mov Disord 2002;17(Suppl):112-119. [PubMed: 11835447]

18. Chung TH, Deane KH, Ghazi-Noori S, et al. Systematic review of antidepressant therapies in Parkinson's disease. Parkinsonism Relat Disord 2003;10:59-65. [PubMed: 14643994]

19. Rosenthal, R. Meta-analytic procedures for social research. Revised edition. Sage Publications; Beverly Hills: 1984.

20. Rosenthal, R. Meta-analytic procedures for social research. Sage Publications; Newbury Park, UK: 1991.

21. Hedges, LV.; Olkin, I. Statistical methods for meta-analysis. Academic Press; New York: 1985.

22. Glass GV. Integrating findings: the meta-analysis of research. Rev Res Educ 1977;5:351.

23. Cohen, J. Statistical power analysis for the behavioral sciences. Academic Press; New York: 1977.

24. Rosnow RL, Rosenthal R. Computing contrasts, effect sizes, and counternulls on other people's published data: general procedures for research consumers. Psychol Methods 1996;1:331-340.

25. Cohen, J. Statistical power analysis for the behavioral sciences. Academic Press; New York: 1977.

26. Sutton, AJ.; Abrams, KR.; Jones, DF., et al. Methods for meta-analysis in medical research. John Wiley \& Sons; New York, NY: 2000.

27. Borenstein, M.; Rothstein, M. Comprehensive meta-analysis manual. Biostat; Englewood, NJ: 1999.

28. Schneider LS, Nelson JC, Clary CM, et al. An 8-week multicenter, parallel-group, double-blind, placebo-controlled study of sertraline in elderly outpatients with major depression. Am J Psychiatry 2003;160:1277-1285. [PubMed: 12832242]

29. Tollefson GD, Bosomworth JC, Heiligenstein JH, et al. A double-blind, placebo-controlled clinical trial of fluoxetine in geriatric patients with major depression. Int Psychogeriatr 1995;7:89-104. [PubMed: 7579025]

30. Allain H, Cougnard J, Neukirch HC, et al. Selegiline in de novo parkinsonian patients: the French selegiline multicenter trial (FSMT). Acta Neurol Scand 1991;84(Suppl):73-78. [PubMed: 1927265]

31. Andersen J, Aabro E, Gulmann N, et al. Anti-depressive treatment in Parkinson's disease: a controlled trial of the effect of nortriptyline in patients with Parkinson's disease treated with 1-dopa. Acta Neurol Scand 1980;62:210-219. [PubMed: 7010875]

32. Aarsland D, Larsen JP, Lim NG, et al. $\alpha 2$-Adrenoreceptor antagonism and serotonin reuptake inhibition in patients with Parkinson's disease and depression. Nord J Psychiatry 2000;54:411-415.

33. Baronti F, Davis TL, Boldry RC, et al. Deprenyl effects on levodopa pharmacodynamics, mood, and free radical scavenging. Neurology 1992;42:541-544. [PubMed: 1549214]

34. Bedard P, Parkes JD, Marsden CD. Nomifensine in Parkinson's disease. Br J Clin Pharmacol 1977;4 (Suppl):187-190.

35. Carrieri PB, Indaco A, Gentile S, et al. $S$-adenosylmethionine treatment of depression in patients with Parkinson's disease. Curr Ther Res 1990;48:154-160.

36. Ceravolo R, Nuti A, Piccinni A, et al. Paroxetine in Parkinson's disease: effects on motor and depressive symptoms. Neurology 2000;55:1216-1218. [PubMed: 11071504]

37. Dell'Agnello G, Ceravolo R, Nuti A, et al. SSRIs do not worsen Parkinson's disease: evidence from an open-label, prospective study. Clin Neuropharmacol 2001;24:221-227. [PubMed: 11479393]

38. Di Rocco A, Rogers JD, Brown R, et al. S-Adenosyl-methionine improves depression in patients with Parkinson's disease in an open-label clinical trial. Mov Disord 2000;15:1225-1229. [PubMed: 11104210]

39. Fischer PA, Baas $H$. Therapeutic efficacy of $R$-(-)-deprenyl as adjuvant therapy in advanced parkinsonism. J Neural Transm 1987;25(Suppl):137-147.

40. Goetz CG, Tanner CM, Klawans HL. Bupropion in Parkinson's disease. Neurology 1984;34:10921094. [PubMed: 6431314] 
41. Hauser RA, Zesiewicz TA. Sertraline for the treatment of depression in Parkinson's disease. Mov Disord 1997;12:756-759. [PubMed: 9380061]

42. Hietanen MH. Selegiline and cognitive function in Parkinson's disease. Acta Neurol Scand 1991;84:407-410. [PubMed: 1776388]

43. Indaco A, Carrieri PB. Amitriptyline in the treatment of headache in patients with Parkinson's disease. Neurology 1988;38:1720-1722. [PubMed: 3054626]

44. Jouvent R, Abensour P, Bonnet AM, et al. Antiparkinsonian and antidepressant effects of high doses of bromocriptine: an independent comparison. J Affect Disord 1983;5:141-145. [PubMed: 6222093]

45. Laitinen L. Desipramine in treatment of Parkinson's disease. Acta Neurol Scand 1969;45:109-113. [PubMed: 4896078]

46. Lees AJ, Shaw KM, Kohout LJ, et al. Deprenyl in Parkinson's disease. Lancet 1977;2:791-795. [PubMed: 71602]

47. Lemke MR. Effect of reboxetine on depression in Parkinson's disease patients. J Clin Psychiatry 2002;63:300-304. [PubMed: 12000202]

48. Meara RJ, Bhowmick BK, Hobson JP. An open uncontrolled study of the use of sertraline in the treatment of depression in Parkinson's disease. J Serotonin Res 1996;4:243-249.

49. Przuntek H, Kuhn W. The effect of R-(-)-deprenyl in de novo Parkinson patients on combination therapy with levodopa and decarboxylase inhibitor. J Neural Transm 1987;25(Suppl):97-104.

50. Rampello L, Chiechio S, Raffaele R, et al. The SSRI, citalopram, improves bradykinesia in patients with Parkinson's disease treated with 1-dopa. Clin Neuropharmacol 2002;25:21-24. [PubMed: 11852292]

51. Rihmer Z, Sátori M, Pestality P. Selegiline-citalopram combination in patients with Parkinson's disease and major depression. Int J Psychiatry Clin Pract 2000;4:123-125.

52. Steur, EN.; Ballering, LA. Combined and selective monoamine oxidase inhibition in the treatment of depression in Parkinson's disease. In: Stern, GM., editor. Advances in neurology. 80. Lippincott Williams \& Wilkins; Philadelphia: 1999.

53. Strang RR. Imipramine in treatment of parkinsonism: a double-blind placebo study. Br Med J 1965;2:33-34. [PubMed: 14305352]

54. Tesei S, Antonini A, Canesi M, et al. Tolerability of paroxetine in Parkinson's disease: a prospective study. Mov Disord 2000;15:986-989. [PubMed: 11009210]

55. Feighner JP, Robins E, Guze SB, et al. Diagnostic criteria for use in psychiatric research. Arch Gen Psychiatry 1972;26:57-63. [PubMed: 5009428]

56. Hamilton M. A rating scale for depression. J Neurol Neurosurg Psychiatry 1960;23:56-62. [PubMed: 14399272]

57. Montgomery SA, Asberg M. A new depression scale designed to be sensitive to change. $\mathrm{Br} \mathrm{J}$ Psychiatry 1979;134:382-389. [PubMed: 444788]

58. Sheikh, JI.; Yesavage, JA. Geriatric Depression Scale (GDS): recent evidence and development of a shorter version. In: Brink, TL., editor. Clinical gerontology: a guide to assessment and intervention. The Haworth Press; New York: 1986.

59. Andersen, J. Depressive tilstande bedømt ved rating scales. University of Copenhagen; Copenhagen: 1975.

60. Alexopoulos GS, Katz IR, Reynolds CF 3rd, et al. The expert consensus guideline series: pharmacotherapy of depressive disorders in older patients. Postgrad Med 2001:1-86. [PubMed: 17205639]

61. Zung WW. A self-rating depression scale. Arch Gen Psychiatry 1965;12:63-70. [PubMed: 14221692]

62. Beck AT, Ward CH, Mendelson M, et al. An inventory of measuring depression. Arch Gen Psychiatry 1961;4:53-63.

63. McNair, DM.; Lorr, M.; Droppleman, LF. Profile of mood states. Educational and Industrial Testing Service; San Diego, CA: 1971.

64. Ackermann RT, Williams JW. Rational treatment choices for nonmajor depressions in primary care: an evidence-based review. J Gen Intern Med 2002;17:293-301. [PubMed: 11972726]

65. Oxman TE, Sengupta A. Treatment of minor depression. Am J Geriatr Psychiatry 2002;10:256-264. [PubMed: 11994212] 
66. van de Vijver DA, Roos RA, Jansen PA, et al. Start of a selective serotonin reuptake inhibitor (SSRI) and increase of antiparkinsonian drug treatment in patients on levodopa. Br J Clin Pharmacol 2003;54:168-170. [PubMed: 12207636]

67. Begg C, Cho M, Eastwood S, et al. Improving the quality of reporting of randomized controlled trials. The CONSORT statement. JAMA 1996;276:637-639. [PubMed: 8773637] 


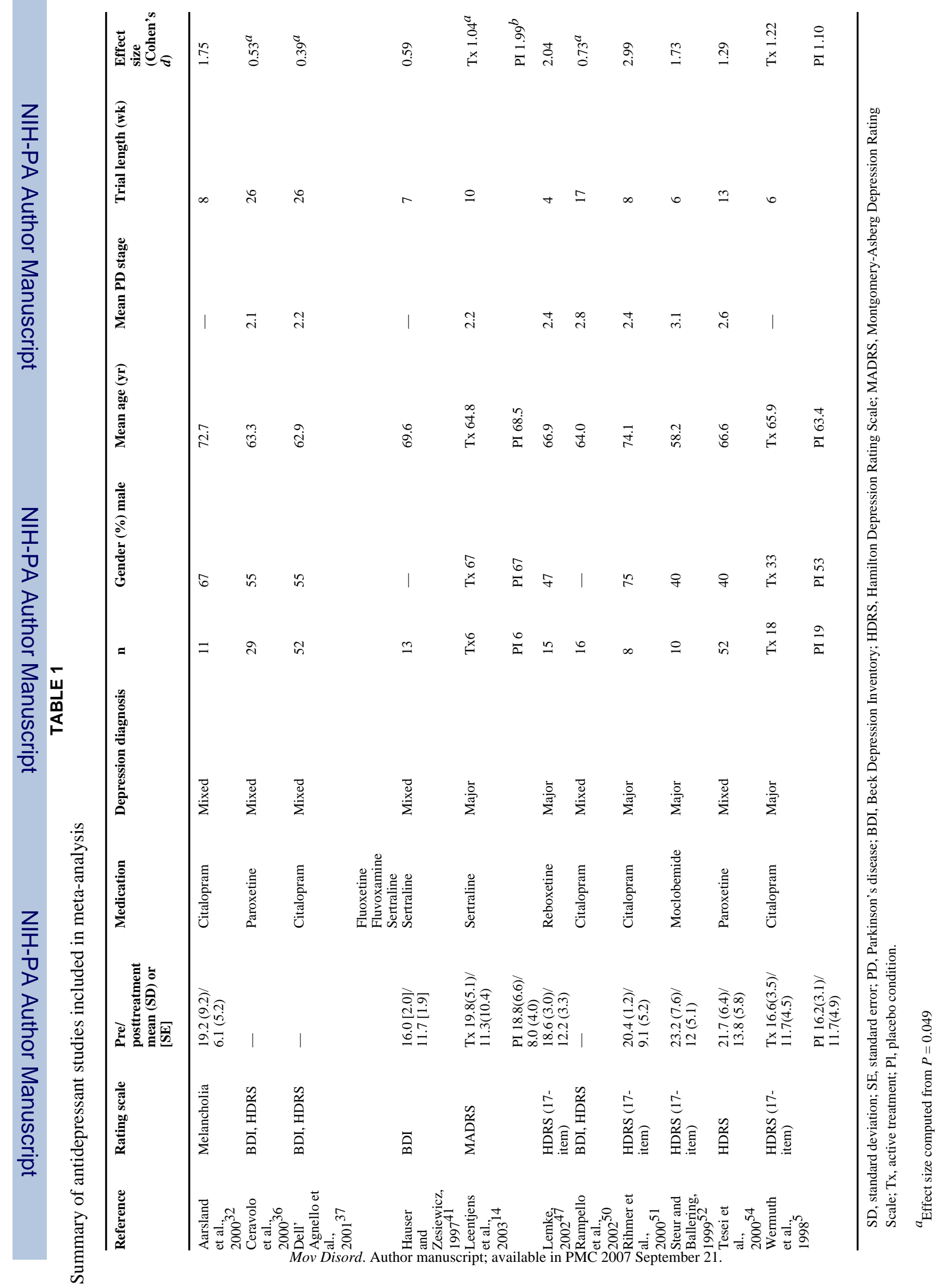


TABLE 2

Tests of categorical model for positive response by treatment assignment in PD patients with depression

\begin{tabular}{lcccc}
\hline Treatment & $\mathbf{k}$ & $\boldsymbol{d}_{+0.93}$ & $\mathbf{9 5 \%} \mathbf{C I}$ & $\boldsymbol{Q}_{\mathbf{w}}$ \\
\hline Active treatment & 11 & +0.93 & $+0.73<\delta<+1.13$ & $29.80^{a}$ \\
Placebo & 2 & +1.18 & $+0.55<\delta<+1.81$ & 0.47 \\
\hline
\end{tabular}

$\overline{Q_{B}}$ (between-class effect) $=0.59, P=0.44$.

Treatment, active treatment vs. placebo administration; $\mathrm{k}$, number of studies in analysis; $d 4$, mean weighted effect size; $95 \% \mathrm{CI}$, 95\% confidence interval for $d_{+} ; Q_{\mathrm{W}}$, within-class effect (test for homogeneity).

$a_{P<0.001}$ 